\title{
Hyper lgM syndrome presenting as chronic suppurative lung disease
}

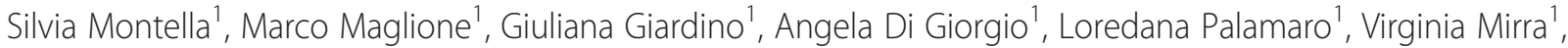 \\ Matilde Valeria Ursini ${ }^{2}$, Mariacarolina Salerno ${ }^{1}$, Claudio Pignata ${ }^{1}$, Carlo Caffarelli ${ }^{3}$ and Francesca Santamaria ${ }^{1 *}$
}

\begin{abstract}
The Hyper-immunoglobulin M syndromes (HIGM) are a heterogeneous group of genetic disorders resulting in defects of immunoglobulin class switch recombination. Affected patients show humoral immunodeficiency and high susceptibility to opportunistic infections. Elevated serum IgM levels are the hallmark of the disease, even though in few rare cases they may be in the normal range. Hyper $\lg M$ is associated with low to undetectable levels of serum IgG, IgA, and IgE. In some cases, alterations in different genes may be identified. Mutations in five genes have so far been associated to the disease, which can be inherited with an X-linked (CD40 ligand, and nuclear factor-kB essential modulator defects) or an autosomal recessive (CD40, activation-induced cytidine deaminase, and uracil-DNA glycosylase mutation) pattern. The patient herein described presented with recurrent upper and lower respiratory infections and evidence of suppurative lung disease at the conventional chest imaging. The presence of low serum IgG and IgA levels, elevated IgM levels, and a marked reduction of in vivo switched memory B cells led to a clinical and functional diagnosis of HIGM although the genetic cause was not identified.
\end{abstract}

\section{Background}

Chronic suppurative lung disease (CSLD) describes a clinical syndrome characterized by chronic endobronchial suppuration with or without high resolution computed tomography (HRCT) evidence of bronchiectasis $[1,2]$. The presenting symptoms are identical to bronchiectasis, and include recurrent chest infections with prolonged moist or productive cough, exertional dyspnoea, features of reactive airway disease, and in some cases growth failure. Digital clubbing, chest wall deformity, adventitious sounds, and/or hyperinflation are the main physical signs. Haemoptysis is rare in children. Once excluded cystic fibrosis (CF), patients should be investigated for other disorders, such as primary immunodeficiencies, aspiration pneumonia, and primary ciliary dyskinesia (PCD) [3].

Hyper-immunoglobulin M syndrome (HIGM) is a rare (incidence, 1 in 100,000 births) primary immunodeficiency $[4,5]$, in which defective B cell isotype switching leads to a phenotype characterized by elevated or normal levels of serum IgM, and low levels of serum IgG, IgA

\footnotetext{
* Correspondence: santamar@unina.it

'Department of Pediatrics, Federico II University, via Pansini 5, Naples 80131 Italy

Full list of author information is available at the end of the article
}

and IgE [5]. Mutations in five different genes, encoding for CD40 ligand, CD40, nuclear factor-kB essential modulator (NEMO), activation-induced cytidine deaminase (AID), and uracil-DNA glycosylase (UNG), have so far been associated to the disease [6-8]. Like in other humoral immunodeficiencies, recurrent respiratory tract infections, potentially leading to bronchiectasis, sinus infections, and ear infections are commonly found in affected patients. Immunoglobulin replacement therapy prevents the progression of the clinical manifestations. In around $40 \%$ of cases opportunistic infections by Pneumocystis carinii is the presenting feature of the syndrome $[9,10]$. However, despite the high susceptibility to airway infections, lung involvement is not commonly characterized by CSLD.

We herein describe the case of a 7-year old girl presenting with symptoms and signs of CSLD, in whom a functional and clinical diagnosis of HIGM was achieved.

\section{Case presentation}

A 7-year old girl complaining of recurrent upper and lower respiratory infections and chronic productive cough was referred to our Department for further diagnostic work-up. She was born to non-consanguineous 
parents after an uneventful 37 weeks pregnancy and had been healthy until the age of three years, when recurrent upper respiratory tract infections started. No other problems were experienced by the patient until the age of 6 years, when she developed an acute pneumonia during a measles infection. Since then, recurrent lower airway infections requiring repeated antibiotic courses and several hospital admissions occurred.

At admission to our Department, the patient appeared in good clinical conditions and physical respiratory examination disclosed any remarkable sign except for mild rhinorrhea and productive cough. Lung auscultation revealed diffuse mild crackles and rhonchi. No symptoms and signs of heart disease were observed. Lung function tests showed no relevant impairment, with forced expiratory volume in 1 second $\left(\mathrm{FEV}_{1}\right)$ and forced vital capacity (FVC) of $106 \%$ and $104 \%$ predicted, respectively. Bronchiectasis in the left and right lower lobes and a consolidation area in the middle lobe were evident at chest HRCT (Figure 1). Tuberculosis, CF, PCD, gastroesophageal reflux disease, alpha-1 anti-trypsin deficiency and atopy were ruled out on the basis of normal or negative results of purified protein derivative test, sweat test, cilia motility and ultrastructure assessment at nasal brushing, prolonged pH-metry, serum alpha-1 anti-trypsin level, and skin prick test and serum IgE levels to the most common food and inhalant allergens. General blood test results were unremarkable, but raised levels of serum IgM (5.63 g/l; normal range, 0.56-2.61) associated with low serum concentration of IgG and IgA (6.06 g/l; normal age-matched range, 6.33-10.16; and $0.33 \mathrm{~g} / \mathrm{l}$; normal range, $0.41-3.15$, respectively) suggested the diagnosis of HIGM, supported by a marked reduction of in vivo switched memory B cells.

The lymphocyte immunophenotyping was assessed by flow cytometry. For flow cytometry analysis, the samples were incubated at $4^{\circ} \mathrm{C}$ for 20 minutes with the appropriate amount of monoclonal antibodies, following the manufacturer's instructions. The mixtures were lysed with ammonium chloride $\left(\mathrm{NH}_{4} \mathrm{Cl}\right)$ lysing solution, then incubated at room temperature for 10 minutes, and finally washed with phosphate buffered saline. Samples were then acquired on a FACSCanto II flow cytometer and analysed with FACSDiva software (BD Bioscience). Fluorescein isothiocyanate-, phycoerythrin-, and peridin chlorophyll protein-coupled antibodies to the following cell-surface proteins were used for flow cytometry: CD19, CD45RA, CD27 (BD Pharmingen or Beckman Coulter) [11]. Results revealed an increase in CD19+ cells (44\%), with complete lack of switched CD27+ B cells. Naïve T cells (CD45RA+) were normally found, but CD40-L expression on $\mathrm{T}$ lymphocytes after proper stimulation was low $(0.2 \%)$, indicating a functional alteration of the machinery required for immunoglobulin class switch recombination (CSR). To rule out a nonrandom X-inactivation, responsible for a CD40-L defect in a female, a methylation assay was performed as previously described [12], and was found normal. Sequence analysis of NEMO and TACI (transmembrane activator and calcium-modulating cyclophilin ligand interactor) revealed no alterations. The mutational analysis of NEMO and TACI was carried out using the polymerase chain reaction test as described by Bardaro et al. [13,14]. Amplification was performed using specific primers for NEMO (forwardGAGGACCAATACCGAGCATC and JF3R reverse primers) and TACI (forward-GTGGTCACTTATTCTAAAGG and reverse-GCAGGATCTTGCCTGCGTC primers). Amplified products were automatically sequenced. ABI Prism dye terminator cycle sequencing kit and an ABI 377 Automated DNA Sequencer were used.

Treatment including daily physiotherapy with nebulized saline was started. Prolonged oral and/or intravenous antibiotics decided on the basis of sputum culture results were prescribed when required. During the follow-up, predominantly Streptococcus pneumoniae and Haemophilus influenzae were isolated at sputum cultures performed on a three-monthly basis. Mycoplasma pneumoniae infection was diagnosed at the age of 11 years. Overall, after the first pneumonia occurred during measles, she had 7 more episodes of chest X-ray

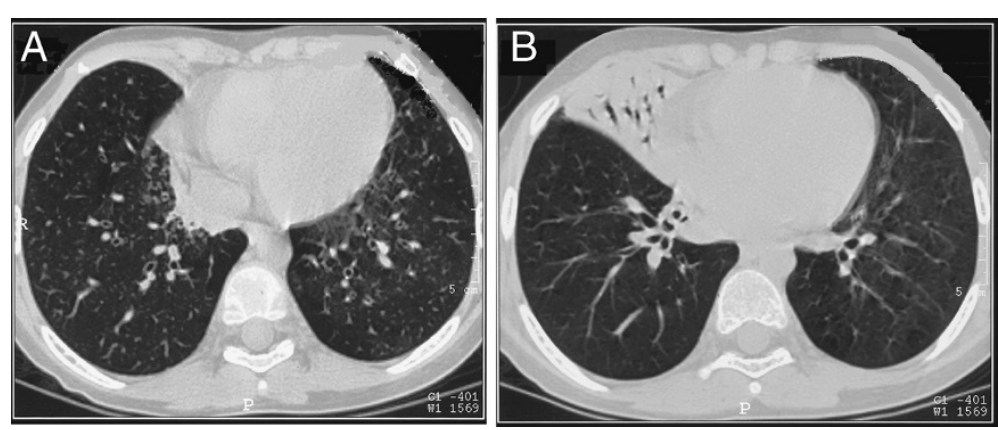

Figure 1 Chest HRCT: bronchiectasis in the left and right lower lobes (A) and a consolidation area in the middle lobe (B) may be observed. 
documented pneumonia. At the age of 12 years she developed a skin lesion on the neck and the histological examination led to a diagnosis of cutaneous B-cells lymphoma successfully treated with at the Oncologic Department. Over the follow-up, the patient was visited about every 3 months, and serum IgM concentration, evaluated every 3-to-6 months, remained persistently elevated, while the low IgG levels progressively decreased over time eventually requiring, at the age of 12 years, the start of intravenous immunoglobulin replacement therapy because of serum IgG levels of $2.93 \mathrm{~g} / \mathrm{l}$ (normal range, 6.40-19.09) (Figure 2). At present, the patient is 16-year old. Her clinical conditions are stable and daily physiotherapy with nebulised saline is still ongoing. Intravenous immunoglobulin replacement therapy is performed approximately every 3 months.

\section{Discussion}

Hyper IgM syndrome is a heterogeneous group of immune defects characterized by normal or increased production of IgM contrasting with a marked decrease or an absence of other isotypes (i.e., IgG, IgA, and IgE). The humoral immunodeficiency results in susceptibility to bacterial infections particularly affecting the respiratory tract. Patients with HIGM often present infections by opportunistic intracellular pathogens, such as Pneumocystis carinii [10,15], Cryptosporidium species [16], Toxoplasma gondii [17], and Mycobacteria species [18]. A common complication of both clinical and subclinical infections is represented by cholangiopathy, which may lead to the development of liver function tests alterations, sclerosing cholangitis, and cirrhosis that may eventually result in cholangiocarcinoma [16]. Chronic intestinal cryptosporidiosis may lead to weight loss, persistent diarrhea, and failure to thrive. Significant neurologic complications, such as cerebral toxoplasmosis $[19,20]$ and cryptococcosis [21], are seen in 10-to$15 \%$ of affected males. Disseminated cytomegalovirus infection may be observed as presenting sign [22]. Moreover, neutropenia may often complicate CD40ligand deficiency, while autoimmune complications are relatively common in patients with defects of CD40 signalling. Malignancies may also occur in patients with HIGM and usually affect the biliary tree $[9,16]$ and the gastrointestinal tract in the form of neuroendocrine tumours [23]. As in other immunodeficiencies, patients also have an increased risk for lymphomas, particularly Hodgkin's disease associated with Epstein-Barr virus infection [24,25]. Indeed, AID deficiency causes the most frequent autosomal recessive alteration of CSR. Marked lymphoid hypertrophy represent a clinical feature of AID deficiency, even though malignant lymphoproliferation has not been ever described. Nevertheless, knock out mice for the UNG gene are prone to B cell lymphomas [26]. Furthermore, lymphomas are common in forms of HIGM due to DNA repair defects such as Ataxia-telangiectasia and Nijmegen Breakage syndrome. Allogeneic hematopoietic cell transplantation can be curative and feasible for the X-linked forms of HIGM without severe cryptosporidial infection and its related complications. If available, transplantation from either an HLA-matched sibling or an HLA-matched unrelated donor can be performed safely [27].

Mutations in five different genes involved in CSR have so far been associated with HIGM. X-linked forms are due to alterations of CD40-ligand and NEMO genes, while autosomal recessive forms are associated with mutations in CD40, AID, and UNG genes. The first recognized and most frequent form of HIGM, accounting for at least $70 \%$ of patients with CSR, is CD40-ligand deficiency $[28,29]$. Up to now, alterations of NEMO have

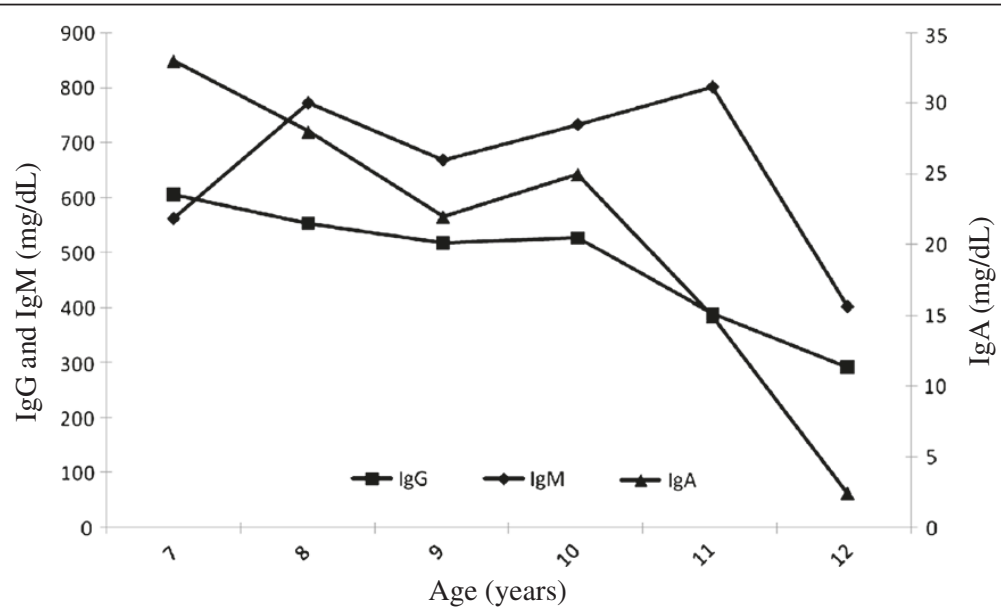

Figure 2 Immunoglobulin levels through the long-term follow-up: serum IgG and IgA progressively decreased to $2.93 \mathrm{~g} / \mathrm{l}$ and $0.02 \mathrm{~g} / \mathrm{l}$, respectively, thus requiring intravenous immunoglobulin replacement therapy. 
been excluded in our patient, while mutations in AID and UNG genes have not. However, we are planning to search for these genetic alterations in the near future.

Specialist referral to diagnose CSLD/bronchiectasis is recommended for children who have either two or more episodes of chronic wet cough per year, or chest radiographic abnormalities persisting for at least 6 weeks after appropriate therapy [30]. In previous large series, the majority of cases of CSLD appeared associated to extrinsic factors, especially childhood respiratory infections (severe pneumonia, pertussis, complicated measles and tuberculosis) that caused chronic endobronchial suppuration with or without bronchiectasis. Singleton et al. reviewed the case histories of 46 Alaskan native children with bronchiectasis born in the 1970s, and concluded that recurrent pneumonia was the major preceding medical condition leading to bronchial damage [31]. In a study by Eastham et al., previous pneumonia was the most common cause found in 93 cases of non-CF bronchiectasis [32]. Likewise, nearly $50 \%$ of children were found to have developed bronchiectasis after tuberculosis or severe pneumonia in a review study by Karakoc et al. [33]. Nowadays, with early immunization and the widespread use of antibiotics in childhood, postinfectious damage is likely to be less relevant than in non-vaccinated children [34]. Nonetheless, detailed investigations must be carried out to determine the underlying cause of the condition [35]. In CSLD, type, extent and severity of lung changes is evaluated by chest imaging techniques, including HRCT or magnetic resonance imaging $[2,36]$.

Our case report highlights the importance to search for noninfectious extrinsic insults or intrinsic defects that predispose to bronchial inflammation or infection resulting in CSLD. These must include aspiration of irritants and congenital disorders, as immunodeficiencies and ciliary defects [37-39]. The identification of the underlying disorder is mandatory in that a delayed diagnosis is associated with more severe disease [40].

\section{Consent}

Written informed consent was obtained from the patient for publication of this Case report and any accompanying images. A copy of the written consent is available for review by the Editor-in-Chief of this journal.

\footnotetext{
Abbreviations

HIGM: Hyper-immunoglobulin M syndromes; CSR: Class switch recombination; CSLD: Chronic suppurative lung disease; HRCT: High resolution computed tomography; CF: Cystic fibrosis; PCD: Primary ciliary dyskinesia; NEMO: Nuclear factor (NF)-kB essential modulator; FEV $\mathrm{F}_{1}$ : Forced expiratory volume in 1 second; FVC: Forced vital capacity.
}

\section{Competing interests}

The author(s) declare that they have no competing interests.

\section{Authors' contributions}

SM has made substantial contributions to conception and design, has been involved in drafting the manuscript, and has given final approval of the version to be published. MM has made substantial contributions to conception and design, has been involved in drafting the manuscript, and has given final approval of the version to be published. GG has made substantial contributions to acquisition of data, has been involved in drafting the manuscript, and has given final approval of the version to be published. ADG has made substantial contributions to acquisition of data, has been involved in revising the manuscript critically for important intellectual content, and has given final approval of the version to be published. LP has made substantial contributions to conception and design, has been involved in revising the manuscript critically for important intellectual content, and has given final approval of the version to be published. VM has made substantial contributions to acquisition of data, has been involved in revising the manuscript critically for important intellectual content, and have given final approval of the version to be published. MVU has made substantial contributions to acquisition of data, has been involved in revising the manuscript critically for important intellectual content, and have given final approval of the version to be published. MS has made substantial contributions to analysis and interpretation of data, has been involved in revising the manuscript critically for important intellectual content, and has given final approval of the version to be published. CP has made substantial contributions to conception and design and analysis and interpretation of data, has been involved in revising the manuscript critically for important intellectual content, and has given final approval of the version to be published. FS has made substantial contributions to conception and design and analysis and interpretation of data, has been involved in drafting the manuscript and revising it critically for important intellectual content, and has given final approval of the version to be published. All authors read and approved the final manuscript.

\section{Author details}

${ }^{1}$ Department of Pediatrics, Federico II University, via Pansini 5, Naples 80131, Italy. ${ }^{2}$ Institute of Genetics and Biophysics Adriano Buzzati-Traverso, IGB-CNR Naples 80131, Italy. 'Department of Pediatrics, University Hospital of Parma, Parma, Italy.

Received: 1 September 2012 Accepted: 14 September 2012 Published: 19 September 2012

\section{References}

1. Chang AB, Byrnes CA, Everard ML: Diagnosing and preventing chronic suppurative lung disease (CSLD) and bronchiectasis. Paediatr Respir Rev 2011, 12:97-103.

2. Montella S, Maglione M, Bruzzese D, Mollica C, Pignata C, Aloj G, Manna A, Esposito A, Mirra V, Santamaria F: Magnetic resonance imaging is an accurate and reliable method to evaluate non-cystic fibrosis paediatric lung disease. Respirology 2012, 17:87-91.

3. Li AM, Sonnappa S, Lex C, Wong E, Zacharasiewicz A, Bush A, Jaffe A: NonCF bronchiectasis: does knowing the aetiology lead to changes in management? Eur Respir J 2005, 26:8-14.

4. PŽron S, Pan-Hammarstršm Q, Imai K, Du L, Taubenheim N, Sanal O, Marodi $L$, Bergelin-Besan on A, Benkerrou M, de Villartay JP, Fischer A, Revy P, Durandy A: A primary immunodeficiency characterized by defective immunoglobulin class switch recombination and impaired DNA repair. J Exp Med 2007, 204:1207-1216.

5. Notarangelo D, Duse M, Ugazio AG: Immunodeficiency with hyper IgM (HIM). Immunodef Rev 1992, 3:101-121.

6. Erdos M, Durandy A, Mar-di L: Genetically acquired class-switch recombination defects: the multi-faced hyper-IgM syndrome. Immunol Lett 2005, 97:1-6.

7. Durandy A, Revy P, Imai K, Fischer A: Hyper-immunoglobulin M syndromes caused by intrinsic B-lymphocyte defects. Immunol Rev 2005, 203:67-79.

8. Notarangelo LD, Lanzi G, Peron S, Durandy A: Defects of class-switch recombination. J Allergy Clin Immunol 2006, 117:855-864.

9. Levy J, Espanol-Boren T, Thomas C, Fischer A, Tovo P, Bordigoni P, Resnick I, Fasth A, Baer M, Gomez L, et al: Clinical spectrum of X-linked hyper-lgM syndrome. J Pediatr 1997, 131:47-54.

10. Winkelstein JA, Marino MC, Ochs H, Fuleihan R, Scholl PR, Geha R, Stiehm ER, Conley ME: The X-linked hyper-IgM syndrome: clinical and 
immunologic features of 79 patients. Medicine (Baltimore) 2003, 82:373-384.

11. Vigliano I, Palamaro L, Bianchino G, Fusco A, Vitiello L, Grieco V, Romano R, Salvatore M, Pignata C: Role of the common g chain in cell cycle progression of human malignant cell lines. Int Immunol 2012, 24:159-167.

12. Fusco F, Mercadante $V$, Miano MG, Ursini MV: Multiple regulatory regions and tissue-specific transcription initiation mediate the expression of NEMO/IKK gamma gene. Gene 2006, 383:99-107.

13. Bardaro T, Falco G, Sparago A, Mercadante V, Gean Molins E, Tarantino E, Ursini MV, D'Urso M: Two cases of misinterpretation of molecular results in incontinentia pigmenti, and a PCR-based method to discriminate NEMO/IKKgamma dene deletion. Hum Mutat 2003, 21:8-11.

14. Fusco F, Bardaro T, Fimiani G, Mercadante V, Miano MG, Falco G, Isra'l A, Courtois G, D'Urso M, Ursini MV: Molecular analysis of the genetic defect in a large cohort of IP patients and identification of novel NEMO mutations interfering with NF-kappaB activation. Hum Mol Genet 2004, 13:1763-1773.

15. Levy DE, Gilliland DG: Divergent roles of STAT1 and STAT5 in malignancy as revealed by gene disruptions in mice. Oncogene 2000, 19:2505-2510.

16. Hayward AR, Levy J, Fachetti F, Notarangelo L, Ochs HD, Etzioni A, Bonnefoy $J Y$, Cosyns M, Weinberg A: Cholangiopathy and tumors of the pancreas, liver and biliary tree in boys with X-linked immunodeficiency with hyper IgM. J Immunol 1997, 158:977-983.

17. Subauste CS, Wessendarp M, Sorensen RU, Leiva LE: CD40-CD40 ligand interaction is central to cell-mediated immunity against Toxoplasma gondii: patients with hyper IgM syndrome have a defective type 1 immune response that can be restored by soluble CD40 ligand trimer. J Immunol 1999, 162:6690-6700.

18. Hayashi T, Rao SP, Meylan PR, Kornbluth RS, Catanzaro A: Role of CD40 ligand in Mycobacterium avium infection. Infect Immun 1999, 67:3558-3565

19. Leiva LE, Junprasert J, Hollenbaugh D, Sorensen RU: Central nervous system toxoplasmosis with an increased proportion of circulating gamma delta T cells in a patient with hyper-lgM syndrome. J Clin Immunol 1998, 18:283-290.

20. Yong PF, Post FA, Gilmour KC, Grosse-Kreul D, King A, Easterbrook P, Ibrahim MA: Cerebral toxoplasmosis in a middle-aged man as first presentation of primary immunodeficiency due to a hypomorphic mutation in the CD40 ligand gene. J Clin Pathol 2008, 61:1220-1222.

21. Simon G, Simon G, Erdšs M, Mar-di L: Invasive Cryptococcus laurentii disease in a nine-year-old boy with X-linked hyper-immunoglobulin $\mathrm{M}$ syndrome. Pediatr Infect Dis J 2005, 24:935-937.

22. Benesch M, Pfleger A, Eber E, Orth U, Zach MS: Disseminated cytomegalovirus infection as initial manifestation of hyper-lgM syndrome in a 15-month-old boy. Eur J Pediatr 2000, 159:453-455.

23. Malhotra RK, Li W: Poorly differentiated gastroenteropancreatic neuroendocrine carcinoma associated with X-linked hyperimmunoglobulin M syndrome. Arch Pathol Lab Med 2008, 132:847-850.

24. Johnson J, Filipovich AH, Zhang K, et al: X-Linked Hyper IgM Syndrome. In GeneReviews [Internet]. Edited by Pagon RA, Bird TD, Dolan CR. Seattle (WA): University of Washington, Seattle; 2007. Available from:http://www.ncbi.nlm. nih.gov/books/NBK1402/.

25. Aloj G, Giardino G, Valentino L, Maio F, Gallo V, Esposito T, Naddei R, Cirillo E, Pignata C: Severe combined immunodeficiences: new and old scenarios. Int Rev Immunol 2012, 31:43-65.

26. Nilsen H, Stamp G, Andersen S, Hrivnak G, Krokan HE, Lindahl T, Barnes DE: Gene-targeted mice lacking the Ung uracil-DNA glycosylase develop Bcell lymphomas. Oncogene 2003, 22:5381-5386.

27. Ziegner UH, Ochs HD, Schanen C, Feig SA, Seyama K, Futatani T, Gross T, Wakim M, Roberts RL, Rawlings DJ, Dovat S, Fraser JK, Stiehm ER: Unrelated umbilical cord stem cell transplantation for X-linked immunodeficiencies. J Pediatr 2001, 138:570-573.

28. Korthauer U, Graf D, Mages HW, BriŽre F, Padayachee M, Malcolm S, Ugazio AG, Notarangelo LD, Levinsky RJ, Kroczek RA: Defective expression of T-cell CD40 ligand causes X-linked immunodeficiency with hyper-IgM. Nature 1993, 361:539-541.

29. Lopez Granados GE, Porpiglia AS, Hogan MB, Matamoros N, Krasovec S, Pignata C, Smith Cl, Hammarstrom L, Bjorkander J, Belohradsky BH, Casariego GF, Garcia Rodriguez MC, Conley ME: Clinical and molecular analysis of patients with defects in micro heavy chain gene. J Clin Invest 2002, 110:1029-1035.

30. Chang AB, Bell SC, Byrnes CA, Grimwood K, Holmes PW, King PT, Kolbe J, Landau LI, Maguire GP, McDonald MI, Reid DW, Thien FC, Torzillo PJ: Chronic suppurative lung disease and bronchiectasis in children and adults in Australia and New Zealand. Med J Aust 2010, 193:356-365.

31. Singleton R, Morris A, Redding G, Poll J, Holck P, Martinez P, Kruse D, Bulkow LR, Petersen KM, Lewis C: Bronchiectasis in Alaska Native children: causes and clinical courses. Pediatr Pulmonol 2000, 29:182-187.

32. Eastham KM, Fall AJ, Mitchell L, Spencer DA: The need to redefine noncystic fibrosis bronchiectasis in childhood. Thorax 2004, 59:324-327.

33. Karakoc GB, Yilmaz M, Altintas DU, Kendirli SG: Bronchiectasis: still a problem. Pediatr Pulmonol 2001, 32:175-178.

34. Montella S, De Stefano S, Sperlì F, Barbarano F, Santamaria F: Increased risk of chronic suppurative lung disease after measles or pertussis in nonvaccinated children. Vaccine 2007, 25:402-403.

35. Montella S, Andreucci MV, Greco L, Barbarano F, De Stefano S, Brunese L, Santamaria F: Clinical utility of CT in children with persistent focal chest abnormality. Eur Respir J 2005, 26:751-752.

36. Maglione M, Montella S, Santamaria F: Chest CTs in primary ciliary dyskinesia: Not too few, but not too many! Pediatr Pulmonol 2012, 47:733-735.

37. Maglione M, Bush A, Montella S, Mollica C, Manna A, Esposito A, Santamaria F: Progression of lung disease in primary ciliary dyskinesia: is spirometry less accurate than CT? Pediatr Pulmonol 2012, 47:498-504.

38. Amorosi S, Russo I, Amodio G, Garbi C, Vitiello L, Palamaro L, Adriani M, Vigliano I, Pignata C: The cellular amount of the common g-chain influences spontaneous or induced cell proliferation. J Immunol 2009 182:3304-3309.

39. Busiello R, Adriani M, Locatelli F, Galgani M, Fimiani G, Clementi R, Ursini MV, Racioppi L, Pignata C: Atypical features of familial hemophagocytic lymphohistiocytosis. Blood 2004, 103:4610-4612.

40. Haidopoulou K, Calder A, Jones A, Jaffe A, Sonnappa S: Bronchiectasis secondary to primary immunodeficiency in children: longitudinal changes in structure and function. Pediatr Pulmonol 2009, 44:669-675.

doi:10.1186/1824-7288-38-45

Cite this article as: Montella et al:: Hyper IgM syndrome presenting as chronic suppurative lung disease. Italian Journal of Pediatrics 2012 38:45.

\section{Submit your next manuscript to BioMed Central and take full advantage of:}

- Convenient online submission

- Thorough peer review

- No space constraints or color figure charges

- Immediate publication on acceptance

- Inclusion in PubMed, CAS, Scopus and Google Scholar

- Research which is freely available for redistribution 